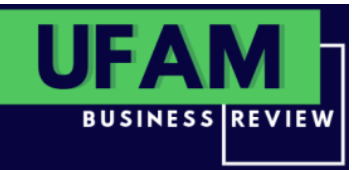

\title{
Práticas Educacionais Inclusivas no Núcleo de Estudos e Pesquisas em Psicopedagogia Diferencial - NEPPD/FACED/UFAM
}

\author{
Inclusive Educational Practices in the Core of Studies and Research in Differential \\ Psychopedagogy - NEPPD / FACED / UFAM

\section{Prácticas Educativas Inclusivas en el Núcleo de Estudios e Investigaciones en Psicopedagogía Diferencial - NEPPD / FACED / UFAM}

\begin{abstract}
Maria Norma Magalhães Stelli ${ }^{1}$ Professora: Secretaria Municipal de Educação, Manaus - SEMED/NEPPD/UFAM/AM nmstelli@gmail.com http://lattes.cnpq.br/0283779010679964 https://orcid.org/0000-0002-8641-8816

Natália dos Santos Chaves 1 Professora: Secretaria Municipal de Educação, Manaus - SEMED/NEPPD/UFAM/AM nataliaschaves@gmail.com http://lattes.cnpq.br/8842131767562242 https://orcid.org/0000-0003-1758-042X

Jeane Vasconcelos de Oliveira ${ }^{1}$ Professora: Secretaria Municipal de Educação, Manaus - SEMED/NEPPD/UFAM/AM jevasconcelos@hotmail.com http://lattes.cnpq.br/9892976271988186 https://orcid.org/0000-0002-0451-889X
\end{abstract}




\title{
Resumo
}

Relatamos no presente trabalho a experiência vivenciada durante as atividades de avaliação/intervenção, realizadas com 38 alunos público-alvo da educação especial de uma escola municipal de ensino fundamental da cidade de Manaus, durante dois semestres de 2017. O estudo, de natureza descritiva, configura-se como relato de experiência e integra o Programa de Atividade Curricular de Extensão (PACE) do Núcleo de Estudos e Pesquisas em Psicopedagogia Diferencial (NEPPD/FACED/UFAM). Fundamentada na teoria de Wallon, a ação envolveu duzentas e quinze pessoas entre equipe de execução, graduandos e comunidade escolar. Como resultado, temos o encaminhamento dos alunos com deficiência para intervenções individualizadas nos laboratórios do NEPPD; atividades pedagógicas específicas aplicadas aos demais e continuidade da ação, possibilitando novos desdobramentos. Considera-se que as atividades contribuíram para a melhoria no processo de ensino/aprendizagem dos alunos, permitindo a articulação dos saberes com o cotidiano dos sujeitos envolvidos na ação, enriquecendo sobremaneira a formação dos graduandos.

Palavras-chave: Ensino-pesquisa-extensão. Atendimento educacional especializado. Práticas pedagógicas inclusivas.

\section{Inclusive Educational Practices in the Core of Studies and Research in Differential Psychopedagogy - NEPPD / FACED / UFAM}

\begin{abstract}
We report in the present work the experience lived during the evaluation / intervention activities carried out with 38 students targeting the special education of a municipal elementary school in Manaus city, during two semesters of 2017. The study, descriptive in nature, It is configured as an experience report and integrates the Extension Curricular Activity Program (PACE) of the Center for Studies and Research in Differential Psychopedagogy (NEPPD / FACED / UFAM). Based on Wallon's theory, the action involved two hundred and fifteen people, including the executive team, undergraduates, and the school community. As a result, we have referral of students with disabilities to individualized interventions in NEPPD laboratories; specific pedagogical activities applied to others and continuity of action, enabling new developments. It is considered that the activities contributed to the improvement of the teaching / learning process of the students, allowing the articulation of knowledge with the daily life of the subjects involved in the action, greatly enriching the formation of the undergraduates.
\end{abstract}

Keywords: Teaching-research-extension. Specialized educational attendance. Inclusive pedagogical practices.

\section{Prácticas Educativas Inclusivas en el Núcleo de Estudios e Investigaciones en Psicopedagogía Diferencial - NEPPD / FACED / UFAM}

\section{Resumen}

Reportamos en el presente trabajo la experiencia vivida durante las actividades de evaluación / intervención llevadas a cabo con 38 estudiantes dirigidos a la educación especial de una escuela primaria municipal en la ciudad de Manaus, durante dos semestres de 2017. El estudio, de naturaleza descriptiva, Está configurado como un informe de experiencia e integra el Programa de Actividad Curricular de Extensión (PACE) del Centro de Estudios e Investigación en 
Psicopedagogía Diferencial (NEPPD / FACED / UFAM). Basado en la teoría de Wallon, la acción involucró a doscientas quince personas, incluido el equipo ejecutivo, estudiantes universitarios y la comunidad escolar. Como resultado, tenemos derivación de estudiantes con discapacidades a intervenciones individualizadas en laboratorios de NEPPD; actividades pedagógicas específicas aplicadas a otros y continuidad de acción, permitiendo nuevos desarrollos. Se considera que las actividades contribuyeron a la mejora del proceso de enseñanza / aprendizaje de los estudiantes, permitiendo la articulación del conocimiento con la vida cotidiana de los sujetos involucrados en la acción, enriqueciendo enormemente la formación de los estudiantes de pregrado.

Palabras clave: Enseñanza-investigación-extensión. Asistencia educativa especializada. Prácticas pedagógicas inclusivas. 


\section{INTRODUÇÃO}

A partir dos pressupostos de Chauí (1995), sobre a organização social brasileira e a inserção social da Universidade em seu tecido social, reflete-se sobre o processo de estruturação das universidades brasileiras. Dentre os pontos colocados pela autora, consideramos para este trabalho, aquele que nos parece de vital importância: a indissociabilidade entre ensino, pesquisa e extensão.

Para Mazzili (2014), o princípio da indissociabilidade entre as três funções citadas, embora incorporado nos estatutos das universidades, pouco tem se concretizado na prática acadêmica. Segundo a autora, a estrutura departamental das universidades acaba por favorecer o desenvolvimento de ações individuais dentro da própria universidade, e o ensino não tem fugido muito da tradição de reprodução do conhecimento. Mazzili (2014) defende ainda que quanto mais qualificado for o docente maior será o seu afastamento das salas de aula. Sobretudo na graduação, esse afastamento é causado por sua dedicação à pesquisa na pós-graduação.

Assim sendo, Mazzili (2014) postula que:

Os projetos de extensão, quando existem, ficam em geral descolados. A estrutura departamental das universidades favorece o desenvolvimento de ações individuais estruturalmente, como se fosse de interesse e responsabilidade exclusiva de seus autores (p. 12).

Objetivando buscar caminhos para a efetivação do princípio da indissociabilidade e da articulação efetiva entre ensino, pesquisa e extensão, o Núcleo de Estudos e Pesquisas em Psicopedagogia Diferencial $^{1}$ da Faculdade de Educação da Universidade Federal do Amazonas NEPPD/FACED/UFAM, desenvolve ações de extensão que privilegiam tanto os acadêmicos dos cursos de graduação da Universidade Federal do Amazonas - UFAM, como a comunidade escolar das redes públicas de ensino da cidade de Manaus.

No sentido de articular as atividades de ensino, pesquisa e extensão como atividades integradoras dentro da universidade, destacamos no presente trabalho, uma das ações desenvolvidas pelo NEPPD, denominada Atendimento Educacional Especializado: uma parceria entre NEPPD e Escola Municipal de Ensino Fundamental Prof. ${ }^{a}$ Regina Vitória Pires Muniz, registrados na Pró-reitoria de Extensão - PROEXTI sob os números: PACE 080_2017-01 e PACE 114/201702, realizada em dois semestres do ano de 2017.

O Projeto surgiu da necessidade de atender aos alunos público-alvo da Educação Especial, devidamente matriculados na referida escola, os quais ao longo do processo educativo apresentaram dificuldades específicas de aprendizagem.

A ação desenvolvida na escola teve início com base nos estudos que abrangem a análise pedagógica e social para que se possa compreender a criança enquanto ser e suas necessidades (MATOS et al., 2012). Para tanto, nos ancoramos na teoria de Henry Wallon, pois a mesma oferece subsídios para aprofundar a reflexão sobre a prática pedagógica, motivando a investigação no campo da educação,

\footnotetext{
${ }^{1}$ NEPPD - Núcleo de Estudos e Pesquisas em Psicopedagogia Diferencial - Pertencente à Faculdade de Educação-FACED da Universidade Federal do Amazonas.
} 
ao mesmo tempo que impõe exigências sobre esta prática, cobrando da escola o atendimento do indivíduo na integridade dos domínios que o constituem (GALVÃO, 1998).

A teoria de Wallon está alicerçada nos fundamentos da "psicogênese da pessoa completa". Tal concepção postula que a criança deve ser compreendida de forma completa, integral. Logo, deve ser percebida em seus aspectos afetivos, biológicos e intelectuais (WALLON, 1998).

Nesse sentido, Wallon (1998) postula que a pedagogia deveria fundamentar as atividades na relação recíproca entre o homem e o seu meio social, considerando as emoções no processo ensinoaprendizagem, defendendo que os professores, para alcançarem êxito na ação pedagógica, deveriam conhecer e entender as crianças em seu desenvolvimento. Esse aspecto atenta de forma específica para a relação professor-aluno e a escola como meio social para a evolução da pessoa humana (GALVÃO, 1998),

[...] dando ao aluno recursos para o desenvolvimento de todas as suas potencialidades, não para usufruí-las individualmente, mas para a transformação social, para a construção de uma sociedade mais justa e igualitária (p.29).

Nesse sentido, o saber escolar não pode ser realizado de forma dissociada do meio físico e social onde a atividade infantil encontra alternativas de realização, mas sim, nutrir-se das possibilidades que ele oferece. Considera, portanto, que para toda ação educacional devem ser levantadas estratégias para o planejamento do processo de avaliação e intervenção pedagógica e psicopedagógica, que devem estar pautadas no respeito às diferenças e a outros padrões estéticos e culturais (WALLON, 1971).

Segundo Boato (2009),

Uma intervenção pedagógica embasada na teoria de Henri Wallon [...] deve dirigir-se à pessoa global e transformar-se em instrumento para seu desenvolvimento, o que pressupõe a integração entre as dimensões afetivas, cognitiva e motora (p. 65).

A ação, objeto deste artigo, iniciou no mês de março de 2017, com a apresentação da proposta do projeto à comunidade acadêmica, seguida de encontros de formação com os colaboradores externos e graduandos, planejamentos para os atendimentos com as crianças, apresentação do projeto à comunidade escolar (gestora, pedagoga, professores e pais/responsáveis das crianças), avaliação pedagógica dos alunos na referida escola, encontros e palestras com a comunidade escolar, produção de pareceres a respeito das avaliações com os alunos, construção e entrega do relatório final.

$\mathrm{O}$ atendimento pedagógico aos alunos com necessidades educacionais especiais teve como ponto principal a atenção para as peculiaridades e limitações apresentadas, contribuindo, deste modo, para o processo de inclusão com base nas políticas públicas educacionais, entre elas, a Política Nacional de Educação Especial na Perspectiva da Educação Inclusiva (BRASIL, 2008).

\section{METODOLOGIA}

Inicialmente, foi encaminhada para o NEPPD uma relação com 38 alunos, constando nela: nome, idade, séries em que estavam matriculados e as queixas apresentadas. Do total de 38 alunos da lista, 
22 tinham como queixa dificuldades de aprendizagem e 16 com queixa de diferentes deficiências e transtornos, tais como: TEA, TDAH, Síndrome de Down e Deficiências Múltiplas. Para a efetivação do trabalho na escola, elaboramos o planejamento das atividades, respeitando o cronograma estipulado dentro do tempo regulamentado pela ação e dos horários da escola.

Os alunos avaliados foram agrupados pelos níveis de escolaridade. Para aqueles em processo de alfabetização, ou seja, do primeiro ao terceiro ano do ensino fundamental os critérios de avaliação obedeceram às diretrizes do Bloco Pedagógico, de acordo com os descritores (MEC, 2015), considerando os níveis de alfabetização postulados por Ferreiro e Teberosky (1999), para quem:

O processo de aprendizagem da lecto-escrita se dá por processos de estruturação e reestruturações de hipóteses, por uma progressiva construção de estruturas cognitivas e que podem ser traduzidas como avanços na compreensão sobre o funcionamento do sistema alfabético (p. 128).

As respostas dos alunos foram classificadas em quatro níveis, quais sejam:

- Pré-silábico: estágio em que a criança não compreende a relação entre a escrita e a pauta sonora; ainda não compreende o que a escrita representa, reproduz traços que se assemelham à escrita padrão; usa movimentos de linhas ondulados para representar a letra cursiva e traços separados para a letra de imprensa, fazendo uso de sinais gráficos arbitrários para representação da escrita.

- Silábico: quando a criança ainda não antecipa quantas letras irá utilizar para escrever, mas ao ler o que escreveu procura ajustar as sílabas orais da palavra às marcas gráficas que notou; pode ocorrer também de o aprendiz já ser capaz de estabelecer uma correspondência entre a quantidade de letras utilizadas e a quantidade de sílabas das palavras, usando ou não letras com e sem valor sonoro convencional;

- Silábico Alfabético: estágio em a criança começa a perceber que uma letra não é suficiente para representar as sílabas e recorre, simultaneamente, a duas hipóteses: a silábica e a alfabética;

- Alfabético: nesse nível, a criança compreende que se escreve com base em uma correspondência entre sons menores que as sílabas (fonemas) e letras. (FERREIRO \& TEBEROSKY, 1999).

Passada a análise das respostas, tivemos um encontro com os pais, com os quais realizamos a entrevista familiar, com o objetivo de levantar dados a respeito da realidade do sujeito a ser atendido referente à relação familiar, aos processos de aprendizagem escolar, aos comportamentos adaptativos e relacionamentos socioafetivos.

As avaliações pedagógicas foram realizadas com base nas informações obtidas e nos planejamentos elaborados. Obedecidos os critérios estabelecidos, a escola encaminhou, via e-mail, para as professoras executoras da ação os nomes dos alunos selecionados para cada avaliação. As avaliações aconteceram sempre às sextas-feiras, na própria escola, nos turnos matutino e vespertino.

As avaliações foram aplicadas pelas professoras integrantes da equipe de execução da ação, sendo apoiadas por acadêmicos do Curso de Pedagogia da Universidade Federal do Amazonas. Ressaltamos que os acadêmicos, depois de selecionados, passaram por formação específica, 
realizada nas dependências do Núcleo de Estudos e Pesquisas em Psicopedagogia Diferencial NEPPD.

Conforme mencionado anteriormente, foram atendidas por esta ação trinta e oito crianças. No quadro a seguir, descrevemos as características do grupo em quatro variáveis: idade, ano escolar, queixa e turno em que estão matriculadas.

Quadro 1 - Alunos para atendimento no PACE 2017/01

\begin{tabular}{|c|c|c|c|c|}
\hline VARIÁVEIS & Idade & Ano escolar & Queixa & $\begin{array}{c}\text { Turno } \\
\text { Matrícula }\end{array}$ \\
\hline \multirow{6}{*}{$\begin{array}{l}\text { No DE ALUNOS POR }^{\circ} \\
\text { VARIÁVEIS/SUBITEM }\end{array}$} & $\begin{array}{l}(\mathbf{0 9}) \\
07 \text { anos }\end{array}$ & $\begin{array}{l}(\mathbf{0 4}) \\
1^{\circ} \text { ano }\end{array}$ & $\begin{array}{l}\text { (22) } \\
\text { Dificuldade de } \\
\text { Aprendizagem }\end{array}$ & $\begin{array}{l}\text { (16) } \\
\text { Matutino }\end{array}$ \\
\hline & $\begin{array}{l}(\mathbf{0 4}) \\
08 \text { anos }\end{array}$ & $\begin{array}{l}(\mathbf{0 6}) \\
2^{\circ} \text { ano }\end{array}$ & $\begin{array}{l}(\mathbf{0 7}) \\
\text { TEA }\end{array}$ & $\begin{array}{l}(\mathbf{0 3}) \\
\text { Vespertino }\end{array}$ \\
\hline & $\begin{array}{l}\text { (11) } \\
09 \text { anos }\end{array}$ & $\begin{array}{l}(\mathbf{1 0}) \\
3^{\circ} \text { ano }\end{array}$ & $\begin{array}{l}(\mathbf{0 3}) \\
\text { TDAH }\end{array}$ & $\begin{array}{l}\text { (01) } \\
\text { Atividade } \\
\text { Adaptada }\end{array}$ \\
\hline & $\begin{array}{l}(\mathbf{0 7}) \\
10 \text { anos }\end{array}$ & $\begin{array}{l}(\mathbf{0 7}) \\
4^{\circ} \text { ano }\end{array}$ & $\begin{array}{l}(\mathbf{0 3}) \\
\text { Síndrome de } \\
\text { Down }\end{array}$ & $\begin{array}{l}\text { (01) } \\
\text { CMEE }\end{array}$ \\
\hline & $\begin{array}{l}(\mathbf{0 7}) \\
11 \text { anos }\end{array}$ & $\begin{array}{l}(\mathbf{0 1}) \\
5^{\circ} \text { ano }\end{array}$ & $\begin{array}{l}\text { (07) } \\
\text { Deficiências } \\
\text { Múltiplas }\end{array}$ & $\begin{array}{l}\text { (17) } \\
\text { Não informado }\end{array}$ \\
\hline & & $\begin{array}{l}\text { (09) } \\
\text { Classe especial }\end{array}$ & & \\
\hline $\begin{array}{c}\text { Total de alunos } \\
\text { encaminhados para } \\
\text { avaliação/intervenção }\end{array}$ & \multicolumn{4}{|c|}{38} \\
\hline
\end{tabular}

Elaboração: as autoras - Fonte: Relatório Final PACE 2017/01

Considera-se o termo dificuldades de aprendizagem amplo, podendo ele ser utilizado para designar diferentes problemas que comprometem a aprendizagem de crianças e adolescentes. Segundo Ohlweiler (2016), tais dificuldades podem configurar "[...] uma situação transitória, não implicando necessariamente em um transtorno" (p.107).

Contudo, as expressões "dificuldade" e "transtorno" de aprendizagem são dois problemas diferentes, que se manifestam e devem ser tratados de maneiras distintas.

Assim sendo, as avaliações pedagógicas e psicopedagógicas aplicadas aos alunos encaminhados foram planejadas no sentido de identificar as dificuldades educacionais apresentadas pelos mesmos, conforme a queixa especificada pela escola. Ressalta-se que algumas das dificuldades de aprendizagem são decorrentes de problemas comportamentais, nesse caso, envolve um trabalho multidisciplinar, fugindo, portanto, do trabalho desenvolvido no NEPPD, que é de cunho exclusivamente pedagógico. 


\section{RESULTADOS E DISCUSSÃO}

O projeto denominado "Atendimento Educacional Especializado: uma parceria entre NEPPD e EMEF Prof. Regina Vitória Pires Muniz", durante seu desenvolvimento, beneficiou duzentas e quinze pessoas dentre pais, alunos, corpo docente da escola, graduandos do curso de pedagogia da Universidade Federal do Amazonas-UFAM, equipe executora e colabores externos do projeto, como se pode observar no quadro 2 , a seguir.

Quadro 2: Número de pessoas beneficiadas pela ação

\begin{tabular}{|c|c|}
\hline ATIVIDADES & $\begin{array}{c}\mathbf{N}^{\circ} \text { DE } \\
\text { PARTICIPAN } \\
\text { TES }\end{array}$ \\
\hline $\begin{array}{l}\text { APRESENTAÇÃO DA PROPOSTA DO PROJETO À COMUNIDADE } \\
\text { ACADÊMICA. }\end{array}$ & 20 \\
\hline $\begin{array}{l}\text { ENCONTROS PARA FORMAÇÃO COM OS ACADÊMICOS DA GRADUAÇÃO, } \\
\text { PÓS-GRADUAÇÃO E COLABORADORES EXTERNOS. }\end{array}$ & 22 \\
\hline $\begin{array}{l}\text { APRESENTAÇÃ̃O DO PROJETO Ȧ COORDENAÇÃO DA ESCOLA } \\
\text { PROFESSORA REGINA VITÓRIA PIRES MUNIZ. }\end{array}$ & 05 \\
\hline $\begin{array}{l}\text { APRESENTAÇÃO DO PROJETO AOS PAIS DOS ALUNOS A SEREM } \\
\text { ATENDIDOS. }\end{array}$ & 33 \\
\hline ENTREVISTA FAMILIAR. & 41 \\
\hline ATENDIMENTO PEDAGÓGICO/PROCESSO AVALIATIVO. & 38 \\
\hline NOVOS ALUNOS INSERIDOS NO SEGUNDO SEMESTRE DE 2017. & 16 \\
\hline $\begin{array}{l}\text { ENCONTROS DE FORMAÇÃO COM OS PAIS E PROFISSIONAIS DA ESCOLA } \\
\text { A RESPEITO DE: FUNDAMENTOS TEÓRICOS, METODOLÓGICOS E LEGAIS } \\
\text { SOBRE INCLUSÃO E NECESSIDADES EDUCATIVAS ESPECIAIS E, } \\
\text { ORIENTAÇÕES A RESPEITO DA "IMPORTÂNCIA DA PARTICIPAÇÃO DOS } \\
\text { PAIS NA VIDA ESCOLAR DOS FILHOS". }\end{array}$ & 40 \\
\hline TOTAL DE SUJEITOS BENEFICIADOS NA AÇÃO & 215 \\
\hline
\end{tabular}

Fonte: Relatório Final PACE 080_2017-01 e PACE 114/2017-02

No contexto do atendimento educacional especializado aos alunos atendidos, durante o processo de intervenção, acontecido no segundo semestre de 2017, 16 novos alunos foram selecionados e encaminhados para participar do processo de avaliação e intervenção, totalizando 54 (cinquenta e quatro) alunos participantes do processo no ano de 2017. No quadro 3, temos o resultado do processo avaliativo realizado com os alunos.

Quadro 3: Resultados sobre o processo de avaliação dos alunos

\begin{tabular}{|c|c|c|c|}
\hline Nome & Idade & $\begin{array}{c}\text { Ano } \\
\text { escolar }\end{array}$ & \multicolumn{1}{|c|}{ Parecer pedagógico } \\
\hline $\begin{array}{c}\text { A. S. DE } \\
\text { M. }\end{array}$ & 11 & $4^{\circ}$ ano & $\begin{array}{l}\text { Em Português, lê pequenos textos e, com mediação, realiza produção textual; } \\
\text { está no nível alfabético, necessitando consolidar esta hipótese. Em matemática, } \\
\text { identifica os numerais e faz relação com as quantidades. Resolve problemas } \\
\text { envolvendo adição e subtração, compreende os conceitos de centena, dezena e } \\
\text { unidade, apresenta bom raciocínio lógico. }\end{array}$ \\
\hline E. J. M. & 09 & $4^{\circ}$ ano & $\begin{array}{l}\text { Apresentou muita resistência em participar das atividades propostas, } \\
\text { aparentando preocupação com questões externas à escola. Realizou com } \\
\text { dificuldade as atividades de Língua Portuguesa; encontra-se no nível Silábico- } \\
\text { Alfabético. Em matemática, tem facilidade em assimilar os conteúdos, }\end{array}$ \\
\hline
\end{tabular}

UFAMBR, Manaus, v. 2, n.1, art. 7, pp. 71-82, janeiro-junho, 2020 http://www.periodicos.ufam.edu.br/ufambr 


\begin{tabular}{|c|c|c|c|}
\hline & & & $\begin{array}{l}\text { apresenta excelente raciocínio lógico matemático, e realiza sem dificuldade as } \\
\text { atividades propostas. }\end{array}$ \\
\hline $\begin{array}{l}\text { E. D, DA } \\
\text { S. S. }\end{array}$ & 07 & $2^{\circ}$ ano & $\begin{array}{l}\text { Apresentou-se tímida, introvertida; não interage, não faz questionamentos; sua } \\
\text { fala é em um tom baixo e infantilizada. Necessitou de mediação para realizar as } \\
\text { atividades propostas. Está no Nível Silábico-Alfabético da escrita. Necessita de } \\
\text { intervenção que proporcione o desenvolvimento da sua autonomia. É } \\
\text { organizada, tem boa coordenação motora e organização espacial. }\end{array}$ \\
\hline M. dos S. & 11 & $4^{\circ}$ ano & $\begin{array}{l}\text { Realizou a maioria das atividades propostas com autonomia. Em Língua } \\
\text { Portuguesa está no Nível Alfabético, consegue ler pequenos textos; na escrita } \\
\text { ainda apresenta erros ortográficos, o que será corrigido ao longo da sua } \\
\text { escolarização através das práticas pedagógicas de leitura e escrita; em } \\
\text { Matemática é capaz de resolver situações-problemas, realiza contagens, } \\
\text { compreende os conceitos de dezena centena e unidade e possui bom raciocínio } \\
\text { lógico-matemático. Apresenta problemas comportamentais, sendo } \\
\text { extremamente indisciplinado, não obedecendo aos comandos. Sugere-se } \\
\text { acompanhamento específico das questões comportamentais, pois as mesmas } \\
\text { têm interferido em seu processo de ensino-aprendizagem. }\end{array}$ \\
\hline $\begin{array}{l}\text { F. de S. } \\
\text { N. }\end{array}$ & 10 & $5^{\circ}$ ano & $\begin{array}{l}\text { Encontra-se no Nível Alfabético de leitura; realiza correspondência entre } \\
\text { fonemas e grafemas; compreende a organização e o funcionamento da escrita, } \\
\text { e é capaz de ler e produzir pequenos textos. Em matemática, reconhece } \\
\text { numerais de } 0 \text { a } 100 \text { e resolve operações matemáticas que envolvem Adição } \\
\text { (sem reservas) e Subtração (sem recursos), compreendendo os conceitos de } \\
\text { dezena, centena e de unidade. Sugerimos intervenções didáticas que favoreçam } \\
\text { a reflexão sobre as palavras e a produção de textos para que seja consolidado o } \\
\text { processo de alfabetização da criança. }\end{array}$ \\
\hline $\begin{array}{l}\text { G. J. B. } \\
\text { da M. }\end{array}$ & 09 & $3^{\circ}$ ano & $\begin{array}{l}\text { Encontra-se no Nível Alfabético; reconhece e escreve corretamente seu } \\
\text { primeiro nome, fazendo uso de letra bastão/imprensa; lê palavras grafadas com } \\
\text { algumas sílabas simples; reconhece numerais de } 0 \text { a } 100 \text { e resolve operações } \\
\text { matemáticas que envolvem Adição (sem reservas) e Subtração (sem recursos). } \\
\text { No entanto, precisa intensificar o processo de alfabetização, para que deste } \\
\text { modo leia e escreva palavras/frases/textos com fluência, mobilizando, com } \\
\text { rapidez, o repertório de correspondência grafofônica já existente e assim, evolua } \\
\text { para o reconhecimento do tema principal de um texto, estabelecendo relações } \\
\text { entre o assunto, a finalidade, o público-alvo e o gênero textual. }\end{array}$ \\
\hline $\begin{array}{l}\text { J. D. X. } \\
\text { R. }\end{array}$ & 10 & $3^{\circ}$ ano & $\begin{array}{l}\text { Encontra-se no Nível Alfabético; reconhece a maioria das letras do alfabeto e } \\
\text { sua forma gráfica; tenta fonetizar a escrita e dar valor sonoro às letras; contudo, } \\
\text { sua escrita apresenta palavras/frases com letras a "menos ou a mais"; reconhece } \\
\text { numerais de } 0 \text { a } 100 \text { e resolve operações matemáticas que envolvem Adição } \\
\text { (sem reservas) e Subtração (sem recursos). Sugere-se dar continuidade à } \\
\text { Intervenção Pedagógica, mediada por todos os envolvidos no seu processo de } \\
\text { ensino-aprendizagem (escola/família/outros) para que, assim, tais dificuldades } \\
\text { apresentadas sejam sanadas. }\end{array}$ \\
\hline J. L. D. & 11 & $3^{\circ}$ ano & $\begin{array}{l}\text { Está no Nível Alfabético; reconhece e escreve seu nome completo, fazendo uso } \\
\text { de letra cursiva; lê palavras grafadas com sílabas simples; parcialmente, suas } \\
\text { produções escritas apresentam correspondência fonética; reconhece numerais } \\
\text { de } 0 \text { a } 100 \text { e resolve operações matemáticas que envolvem Adição (sem } \\
\text { reservas) e Subtração (sem recursos). Sugerimos a continuidade de Intervenção } \\
\text { Pedagógica no âmbito da Língua Portuguesa, envolvendo escrita, estruturação } \\
\text { e delimitação de cada palavra em uma frase; também a produção textual de }\end{array}$ \\
\hline
\end{tabular}




\begin{tabular}{|c|c|c|c|}
\hline & & & $\begin{array}{l}\text { forma oral e escrita e; no âmbito da Matemática, a intensificação de resoluções } \\
\text { problemas que envolvam as operações fundamentais. }\end{array}$ \\
\hline $\begin{array}{l}\text { K. da S. } \\
\text { do N. }\end{array}$ & 07 & $1^{\circ}$ ano & $\begin{array}{l}\text { Encontra-se no Nível Alfabético, estabelecendo correspondências grafofônicas } \\
\text { entre letras e sons, embora com erros ortográficos. Em matemática, apresentou } \\
\text { grande facilidade em assimilar os conteúdos, com excelente raciocínio lógico } \\
\text { matemático, realizou sem dificuldade as atividades propostas. A criança } \\
\text { apresenta algumas características de TDAH, (ressalta-se que o diagnóstico é } \\
\text { essencialmente clínico. Portanto, sugerimos investigação feita por uma } \\
\text { equipe multidisciplinar). Ao professor, indicamos o uso de estratégias, como } \\
\text { utilizar recursos audiovisuais, computadores, vídeos, DVD; evitar que o aluno } \\
\text { sente junto a portas, janelas e nas últimas fileiras da sala de aula; permitir que o } \\
\text { aluno se levante em alguns momentos, previamente combinados entre ele e o } \\
\text { professor. }\end{array}$ \\
\hline $\begin{array}{l}\text { L. de L. } \\
\text { da S. }\end{array}$ & 09 & $4^{\circ}$ ano & $\begin{array}{l}\text { Está no Nível Alfabético. É capaz de ler e produzir pequenos textos, utiliza a } \\
\text { letra cursiva na escrita, fazendo diferenciação no uso das letras maiúsculas e } \\
\text { minúscula. Em matemática, identifica os numerais de } 0 \text { a } 100 \text {, compreende os } \\
\text { conceitos de unidade, dezena e centena, resolve situações problemas } \\
\text { envolvendo adição e subtração. }\end{array}$ \\
\hline $\begin{array}{l}\text { L. R. A. } \\
\text { de O. }\end{array}$ & 07 & $2^{\circ}$ ano & $\begin{array}{l}\text { Participou timidamente do processo de intervenção, pois, embora respondesse } \\
\text { a tudo que lhe foi perguntado, falava com voz baixa. Respondeu com mediação } \\
\text { todas as questões apresentadas de forma correta, estando no Nivel Alfabético } \\
\text { do processo de alfabetização. Realiza com facilidade as atividades envolvendo } \\
\text { adição e subtração, reconhece os numerais e as quantidades e resolve problemas } \\
\text { simples. }\end{array}$ \\
\hline $\begin{array}{l}\text { M. G. da } \\
\text { S. B. }\end{array}$ & 09 & $3^{\circ}$ ano & $\begin{array}{l}\text { Encontra-se no Nível Silábico-Alfabético. Em suas produções escritas faz uso, } \\
\text { ora de letra cursiva, ora de imprensa/bastão. Apresenta linguagem oral com } \\
\text { "pouca dicção", dificultando a compreensão do que se refere e/ou, apresentando } \\
\text { suas produções escritas da forma como fala. }\end{array}$ \\
\hline $\begin{array}{l}\text { N. G. dos } \\
\text { R. }\end{array}$ & 08 & $2^{\circ}$ ano & $\begin{array}{l}\text { O aluno apresentou-se inquieto, preferindo isolar-se; ignora as orientações e } \\
\text { comandos; não responde oralmente ao que lhe é perguntado, ou seja, não } \\
\text { realizou a maioria das atividades propostas. Percebeu-se, contudo, seu interesse } \\
\text { em atividades interativas com uso de computador, podendo este instrumento ser } \\
\text { usado como ferramenta para o favorecimento de seu processo ensino- } \\
\text { aprendizagem. }\end{array}$ \\
\hline $\begin{array}{l}\text { N. da S. } \\
\text { D. }\end{array}$ & 07 & $2^{\circ}$ ano & $\begin{array}{l}\text { Apresentou problemas comportamentais, recusando-se a obedecer aos } \\
\text { comandos dados. Quanto aos conteúdos trabalhados em Língua Portuguesa está } \\
\text { no nível Silábico Alfabético, escrevendo ora com letra de imprensa ora com } \\
\text { letra cursiva; não faz a separação das palavras dentro de uma frase, reconhece } \\
\text { e identifica as letras do alfabeto. Em Matemática realiza operação de adição e } \\
\text { subtração com mediação, reconhece os numerais, necessitando aprofundar os } \\
\text { conceitos de dezena, centena e unidade. }\end{array}$ \\
\hline $\begin{array}{l}\text { R. da M. } \\
\text { L. }\end{array}$ & 09 & $3^{\circ}$ ano & $\begin{array}{l}\text { Encontra-se no nível silábico. Utiliza, ao escrever, uma letra para cada emissão } \\
\text { sonora, inclusive na escrita do próprio nome, o que reflete uma dificuldade para } \\
\text { ler textos escritos por outras pessoas, pois acabam "sobrando" letras. Na escrita, } \\
\text { utiliza a letra bastão em tamanhos desproporcionais; não respeita os limites do } \\
\text { papel, troca letras como p/, escreve outras de forma espelhada, e apresenta } \\
\text { também dificuldades em copiar do quadro. Em Matemática identifica os } \\
\text { numerais de } 0 \text { a 10, porém, não compreende ainda os conceitos de dezena e } \\
\text { centena; percebeu-se grande dificuldade em realizar contagem de pequenas } \\
\text { quantidades. Sugere-se o encaminhamento para atendimento individualizado no } \\
\text { NEPPD. }\end{array}$ \\
\hline
\end{tabular}

Elaboração: as autoras.

Fonte: Relatório Final PACE 080_2017-01 e PACE 114/2017-02

UFAMBR, Manaus, v. 2, n.1, art. 7, pp. 71-82, janeiro-junho, 2020 http://www.periodicos.ufam.edu.br/ufambr 


\section{ENCAMINHAMENTOS}

Após as avaliações, os alunos com deficiência e/ou maiores comprometimentos foram encaminhados para o Núcleo de Estudos e Pesquisas em Psicopedagogia Diferencial - NEPPD, para atendimento especializado nos Laboratórios do NEPPD, a saber: Laboratórios de Desenvolvimento Humano; Laboratório de Psicomotricidade; Laboratório de Teoria e Práticas da Aprendizagem Humana e Laboratório das Dificuldades Específicas da Aprendizagem, os quais se encontram em processo de intervenção. Os demais alunos passaram por processo de intervenção com atividades pedagógicas e psicopedagógicas específicas de acordo com as dificuldades apresentadas. Ressalta-se que a equipe executora deu continuidade à ação, possibilitando novos desdobramentos, como o acompanhamento periódico dos alunos até o final do ano letivo.

\section{CONSIDERAÇÕES FINAIS}

O Projeto se desenvolveu de forma harmônica entre os envolvidos no processo, culminando no alcance dos objetivos propostos, dentre eles, o subsídio de fundamentos teóricos, metodológicos e legais para o processo de ensino-aprendizagem de crianças com necessidades educacionais especiais aos profissionais da referida escola.

O desenvolvimento deste projeto possibilitou, a todos os envolvidos no processo, a compreensão da importância que teve a intervenção pedagógica/psicopedagógica, embasada na teoria de Henri Wallon com alunos com necessidades educacionais especiais. Tendo em vista que esta teoria orienta o trabalho com o ser humano de forma global, o projeto possibilitou a realização de atividades envolvendo a afetividade, as emoções e a cognição, culminando no pleno desenvolvimento dos alunos.

As intervenções realizadas foram experiências significativas para todos os colaboradores envolvidos, pois nos proporcionaram uma visão diferente e mais ampla em relação às deficiências apresentadas pelos alunos, sobretudo às singularidades das crianças autistas.

Algumas dificuldades enfrentadas nos primeiros momentos, como a falta de um local adequado para o desenvolvimento das ações, além da carga horária destinada às atividades e a rotina da escola, foram contornadas com a disponibilidade da equipe pedagógica da escola, sempre pronta a favorecer o desenvolvimento da ação. Essa conduta permitiu refletir sobre a intervenção pedagógica e psicopedagógica para alunos com necessidades educacionais especiais enquanto ação desafiadora, que exige conhecimento específico, reflexão, e sobretudo, domínio das técnicas de intervenção.

Ressalta-se que todos os alunos evidenciaram melhora em seus comportamentos em relação ao início das intervenções. Buscamos adequar as diferentes maneiras de intervenção junto aos alunos com deficiências, interpretando comportamentos e gradativamente oferecendo atividades estimulantes - condições necessárias - para que eles se desenvolvessem, descobrindo novos modos de comunicação e relacionamento com os outros e com o meio, promovendo um melhor desempenho em suas tarefas cotidianas e a funcionalidade de suas ações.

O trabalho também possibilitou espaço aos discentes das áreas de educação da Universidade Federal do Amazonas - UFAM, para uma atuação satisfatória como equipe interdisciplinar, ou seja, buscando uma única linguagem, e tendo como tarefa principal lidar com o público-alvo da 
educação especial. Assim, através das intervenções pedagógicas, foi possível proporcionar aos alunos e suas famílias, maior interação social com o seu meio e melhor convivência no cotidiano. Dessa forma, este trabalho buscou na obra de Henri Wallon, em sua Teoria das Emoções e da Psicogênese, embasamento para uma intervenção pedagógica que contemplasse todos os aspectos do desenvolvimento do aluno, de modo a proporcionar-lhe um ambiente que oferecesse condições de real crescimento e participação efetiva no meio social.

\section{REFERÊNCIAS}

Brasil. Ministério da Educação. (2008). Política Nacional de Educação Especial na Perspectiva da Educação Inclusiva. Brasília. . (2015). Síntese das diretrizes curriculares nacionais para a educação básica. Ministério da Educação. Brasília.

Boato, E. M. (2009). Contribuições da teoria das emoções e da psicogênese de Henry Wallon na intervenção pedagógica em crianças com deficiência mental associada a deficiência visual. 125 f. Dissertação (Mestrado). Universidade Católica de Brasília, 2009.

Chauí, M. (1995). Ética e universidade. In: . Universidade e sociedade. Brasília: Andes.

Ferreiro, E.; Teberosky, A. Psicogênese da língua escrita. Trad. Diana M. Linchestein et al. Porte Alegre: Artes Médicas.

Galvão, I. (1998). Henri Wallon: uma concepção dialética do desenvolvimento infantil. Petrópolis, RJ: Vozes.

Matos, M. A. de S.; et al. (2012). A contribuição de Wallon para o desenvolvimento e aprendizagem da criança autista. In: Elo: diálogos em extensão universitária. vol.1, n.1 (dez/jul.) 2012. Viçosa, MG: Pró-Reitoria de Extensão e Cultura.

Mazzili, S. (1998). Notas sobre indissociabilidade entre ensino-pesquisa-extensão. In: RIZZINI, I. O Século perdido. Rio de Janeiro: Anais.

Rotta, N. T.; Hohlweiler, L.; Riesgo, R. dos S. (Orgs.). (2016). Transtornos da aprendizagem: abordagem neurobiológica e multidisciplinar. 2. ed. Porto Alegre: Artmed, 2016.

Wallon, H. (1998). As origens do caráter na criança. São Paulo: Difusão Européia do Livro. . (1998). A Evolução psicológica da criança. São Paulo: Martins Fontes. 